\title{
Perceptions of dominance following glimpses of faces and bodies
}

\author{
Nicholas O Rule ${ }^{1}$, Reginald B Adams $\mathrm{Jr}^{2}$, Nalini Ambady ${ }^{3}$, Jonathan B Freeman ${ }^{4}$ \\ ${ }^{1}$ Psychology Department, University of Toronto, 100 St George Street, Toronto, ON M5S 3G3, \\ Canada; e-mail: rule@psych.utoronto.ca; ${ }^{2}$ Department of Psychology, The Pennsylvania State \\ University, 464 Moore Bldg, University Park, PA 16802-3106, USA; ${ }^{3}$ Psychology Department, \\ Stanford University, Jordan Hall, BIdg 420, Stanford, CA 94305, USA; ${ }^{4}$ Department of \\ Psychology, Tufts University, 490 Boston Avenue, Medford, MA 02155, USA \\ Received 27 May 2011, in revised form 4 April 2012
}

\begin{abstract}
Dominance is one of the most ecologically important social traits that humans express and perceive. Here, we examined perceivers' capacity to judge dominance under physical and temporal constraints. In study 1, dominant, neutral, and submissive poses of otherwise non-expressive faces and impoverished facial outlines were judged after exposure for $27 \mathrm{~ms}, 40 \mathrm{~ms}, 94 \mathrm{~ms}$, or at a selfpaced rate (approximately $2000 \mathrm{~ms}$ ). Perceivers' judgments of dominance were significantly more accurate than chance guessing for exposures of $40 \mathrm{~ms}$ and greater, with no significant increase in accuracy given additional viewing time. In study 2 , we replaced faces with bodies and figural outlines of bodies. Perceivers' judgments were again better than chance for exposures of $40 \mathrm{~ms}$ and greater, but significant increases in accuracy were observed for durations of $94 \mathrm{~ms}$ and at a self-paced rate. Finally, in study 3 , we combined studies 1 and 2 to allow comparisons across stimuli. Results showed that judgments of dominance from the faces were significantly more accurate than were those of the bodies, and judgments of full stimuli were more accurate than were those of outlines. These data extend our knowledge of the efficient and accurate perception of social cues from nonverbal behavior.
\end{abstract}

Keywords: dominance, person perception, face perception, accuracy, ecological theory

\section{Introduction}

Whether people-watching from a park bench or interrogating someone in an interview, we are always forming impressions of others. Whereas some of our judgments of others are made from careful and deliberate contemplation, we form many of our impressions quickly and with limited information (see Ambady et al 2000). Many factors contribute to how we make these impressions: the availability of cognitive resources (Macrae et al 1994), motivations (Neuberg and Fiske 1987), and the domain of judgment (Lassiter et al 2009), to name a few.

One dimension of great social importance that also has relatively clear-cut perceptual cues is social dominance. Evaluations of social dominance are critical among not only humans but all primate species (Mazur 2005). Displays of status help to organize social groups by providing hierarchies that assign roles to different members of the group (eg Schmid Mast 2001). Indeed, perceptions of dominance have previously been found to be highly consistent and predictive of important outcomes across perceivers (eg Keating et al 1981; Rule et al 2010), perhaps indicating that individuals are somewhat predisposed towards evaluating dominance and submission (Mazur 2005). Dominance can be readily judged from nonverbal behaviors (eg Schmid Mast and Hall 2004) and can have influences on the perception of important social traits, such as attractiveness and affect (Keating 1985; Ohman 1986; Raines et al 1990; see also Olson and Marshuetz 2005). Thus, perceptions of dominance hold high ecological validity for interpersonal perception (Mazur 2005), are relatively legible from nonverbal cues (Hall et al 2001), and can effect important social consequences (Mueller and Mazur 1996). 
The ecological theory of perception suggests that human perceptual abilities have been shaped by their ecological utility (Gibson 1979; McArthur and Baron 1983; Zebrowitz and Collins 1997). These perceptions cause us to become attuned to relevant stimuli that, in turn, afford us the opportunity to act as a result of perceiving them. The perception of cues to dominance fits well within this framework of functional affordances (see McArthur and Baron 1983; Zebrowitz and Collins 1997). For the reasons described above, correctly perceiving the dominant and submissive displays of another person or animal can be critical to our survival. It is therefore likely that people possess a pronounced capacity for perceiving displays of dominance under very challenging conditions and constraints. We test this in the present work by examining the ability of perceivers to accurately detect dominant and submissive cues under severely restricted viewing conditions (ie to distinguish between dominant and submissive nonverbal displays at levels significantly greater than what would be expected by chance). ${ }^{(1)}$

Of all the nonverbal channels of communication, the face and head are regarded as the most expressive and, perhaps, the most important (eg Rinn 1991; Zebrowitz 1997). Cues from the face signal both dispositions as well as intentions (eg Baron-Cohen et al 1996). Previous studies examining facial cues to dominance and submission have identified the vertical orientation of the head (ie its level of tilt) as an important feature in communicating intentions and dispositions (Kappas et al 1994; Mignault and Chaudhuri 2003; see also Chiao et al 2008; Hall et al 2001). We therefore measured perceivers' ability to judge dominance and submission from the face.

Another nonverbal medium by which dominance and submission may be communicated is the body. Both traits (eg size) and states (eg motions) of the body can signal dominance (Mazur 2005). In addition, particular stances are known to effectively display dominance and submission, such as the occupation of more versus less physical space, respectively (Burgoon et al 1984; Burgoon and Dunbar 2006; Tiedens and Fragale 2003). Bodily cues to dominance and submission may be particularly salient to perceivers because of their potentially large spatial presence and dynamic nature and because they may signal immediate physical threats. For instance, whereas cues in the face may signal intentions and forthcoming actions, cues in the body may signal movements and actions in progress (eg de Gelder and Tamietto 2011). It is therefore possible that bodily cues to dominance and submission will be more easily perceived than will facial cues. However, given the central role of faces in human social perception, including their specialized processing in the brain (Moscovitch et al 1997) and broad capacity for expression (Zebrowitz 1997), it is possible that perceivers may utilize face information more than body information. It is also possible that individuals might be more adept at expressing dominance from the face than from the body. To test this, we directly compared dominance judgments based on the face and body in the present work.

Consistent with the ecological view of social perception (eg McArthur and Baron 1983), it is reasonable to expect that perceivers should be very efficient in perceiving targets' dominance from observations of their bodies and faces. To measure the efficiency of these judgments, we investigated perceivers' ability to accurately (ie significantly better than chance guessing) judge dominance and submission from facial and bodily displays under time constraints and when the stimuli were impoverished so as to include only major high spatial-frequency contours (ie removing identifying details in clothing and facial appearance to provide a clearer signal of the key structural information). Previous research has shown that many of our impressions can be influenced by exposure time. For instance, Bar et al (2006)

(1) In the present work we use the term "accuracy" to refer to perceivers' ability to read the targets' intended displays of dominance. An important caveat to this is that the targets were not necessarily feeling, experiencing, or naturally enacting these behaviors when photographed. Thus, "accuracy" here does not refer to the internal states of the targets but rather to perceivers' capacity to identify cues based on simulations of dominance that occur in the natural world. 
found that participants' judgments of how threatening a face appeared were consistent when the face was viewed for $39 \mathrm{~ms}$ and $1700 \mathrm{~ms}$ but not consistent for impressions based on just $26 \mathrm{~ms}$ of viewing time. Although this was true for threat judgments, participants' judgments of intelligence were not consistent across these same viewing durations. Whereas these judgments of threat and intelligence were based on subjective opinions, other studies have shown similar consistency across exposure times for judgments with objective outcomes. For example, sexual orientation can be judged with above-chance accuracy from exposures as brief as $40 \mathrm{~ms}$ with no increase in accuracy for longer viewing times (Rule et al 2009a).

For the present investigation, we created face and body stimuli that depicted dominance, submission, and neutrality and presented these to participants at three speeded durations and at a self-paced rate. Since the cues to dominance and submission are fairly well circumscribed, explicit, and obvious, we chose to use high-signal, posed stimuli here-rather than, for example, photographing individuals after dominating (or being defeated by) another person in a contest. Thus, we focused more on the capacity for perceivers to detect important and obvious behavioral cues under physical and temporal constraints as opposed to measuring the natural manifestation of these cues according to various social conditions. Moreover, in contrast to earlier work which tested the consensus of impressions of traits like dominance from neutral faces (eg Rule et al 2009b), here we examined the accuracy of judgments of dominance by using stimuli that objectively conveyed cues associated with actual dominant and submissive behaviors (see Carney et al 2005, 2010; Hall et al 2005; Mazur 2005). Compared to many other traits and dispositions, dominance is interesting because it shows stable differences between individuals, yet also has discrete behavioral manifestations that display its relative levels (eg Goldberg et al 2006). We therefore capitalized on this welldefined nature of dominance signals in the current work.

In study 1, we asked participants to judge dominance and submission from the posed faces, and in study 2 from the posed bodies. In both studies, participants viewed the targets at $27 \mathrm{~ms}, 40 \mathrm{~ms}, 94 \mathrm{~ms}$, or a self-paced rate (durations found to be relevant perceptual thresholds in previous work on social perception-Bar et al 2006; Rule and Ambady 2008; Rule et al 2009b). Unlike the judgments of perceptually ambiguous cues (such as those supporting distinctions based on sexual orientation), we expected that accuracy might significantly increase as exposure duration increases for the judgment of the intentionally- and explicitlyposed cues to dominance used here. That is, although deliberation over difficult judgments (like discerning sexual orientation from a set of conflicting or ambiguous cues-Rule et al 2008) has been found to impair accuracy (Rule et al 2009a), easy judgments, such as those based on obvious cues like those used here-should become more effective with increased viewing time (see Dijksterhuis et al 2006).

We therefore compared the accuracy of these judgments across exposure time and channel of presentation (the face or the body). Moreover, judgments were made either from full face (study 1a) and body (study 2a) stimuli, or from stimuli in which the low spatial frequency information was removed to reveal only outlines of the face (study 1b) and body (study $2 \mathrm{~b}$ ). Finally, we combined all of these conditions into a single design to allow comparisons between the face, body, full, and outline stimuli employed (study 3 ). We expected that perceivers would be able to accurately judge dominance and submission from quick but supraliminal (ie $40 \mathrm{~ms}$ and above) exposures. Further, we hypothesized that the accuracy of dominance and submission judgments may increase with greater viewing time because the explicit nature of dominance cues may allow them to be better resolved at longer exposures (Burgoon et al 1984; Kappas et al 1994; Mignault and Chaudhuri 2003). Indeed, although previous work has shown that deliberation impairs the judgment of ambiguous stimuli, it may assist the accuracy of judgments of cues that are obvious (eg Macrae and Martin 2007). Moreover, given that 
changes among the limbs of the body may be more visually obvious than changes among the features of the face-but that the face plays a special role in perception, expression, and communication among humans (eg Zebrowitz 1997) — we tested whether the face or the body would provide for more-accurate judgments of dominance and submission. Finally, we expected that full stimuli would allow for greater accuracy than would stimuli that had been impoverished, but, in light of the functional affordances provided by dominance cues, we expected both types of stimuli to be judged significantly better than chance.

\section{Study 1}

We began by asking participants to assess dominance expressed in a series of faces that were intentionally posed to appear dominant, submissive, or neutral. To test the accuracy of dominance perception under perceptual constraints, participants made these judgments after seeing the faces for either a brief $(27 \mathrm{~ms}, 40 \mathrm{~ms}$, or $94 \mathrm{~ms}$ ) or an unlimited (self-paced) amount of time. In study 1a, participants judged photos of faces. In study $1 \mathrm{~b}$, additional visual constraints were added: participants judged the same photos after they had been processed to remove details of the faces, which left only the major outlines of the face visible.

\subsection{Study 1a. Method}

2.1.1 Participants. Sixty-four undergraduates participated for partial credit in an introductory psychology course or for monetary compensation. Equal numbers of participants $(n=16)$ were randomly assigned to one of four conditions based on presentation time: $27 \mathrm{~ms}$ exposure, $40 \mathrm{~ms}$ exposure, $94 \mathrm{~ms}$ exposure, or self-paced exposure.

2.1.2 Stimuli. Twenty Caucasian undergraduate males posed making dominant, submissive, and neutral facial expressions in exchange for partial credit in an introductory psychology course, yielding 60 stimuli in total. The targets were photographed under conditions standardized for lighting, camera angle, distance from camera, and background. None of the targets wore any facial adornments, such as jewelry, glasses, or facial hair. They were instructed on how to pose prototypical expressions of dominance and submission based on previous work showing that direct eye gaze and an upward head tilt convey dominance whereas averted eye gaze and a downward head orientation communicate submission (Chiao et al 2008; Mignault and Chaudhuri 2003; see figure 1 for sample stimuli). The photographs were further standardized by cropping each face at its extremes (ie bottom of neck, top of head, and left and right extremes of hair or ears), converting them from color to grayscale, and standardizing the photos to be roughly equal in size (all stimuli subtended between $9.21 \mathrm{deg}$ and 16.85 deg of visual angle).

2.1.3 Procedure. Participants were instructed that they would be seeing a series of faces appear on the computer screen and that they would be rating each face along a scale from 1 (very submissive) to 8 (very dominant). Participants in the self-paced condition then began rating the faces, which appeared in a random order, for a total of 60 trials (20 for dominant faces, 20 for neutral faces, and 20 for submissive faces - ie 1 trial per face). Participants in the time-limited conditions, however, were given three practice trials to orient them with the timing of the task. They were further instructed that they would see a series of images before making their judgment about the face: a fixation cross to cue attention (presented for $250 \mathrm{~ms}$ ), the target face (presented for a condition-dependent duration), a piece of "abstract art" (a backward mask matched for high and low spatial frequencies, presented for $94 \mathrm{~ms}$ ), and finally the screen prompting them for their rating of the face (see figure 2). Participants in all conditions were instructed to work as quickly and accurately as possible. Analysis of participants' response latencies indicated that the mean presentation time for faces in the self-paced condition was $2011 \mathrm{~ms}(\mathrm{SE}=206 \mathrm{~ms})$. 

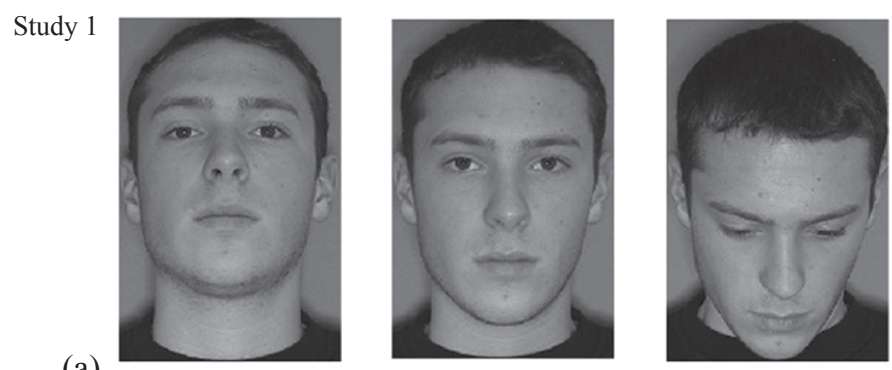

(a)
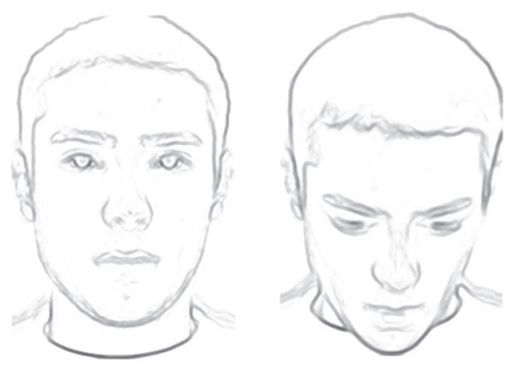

(b)
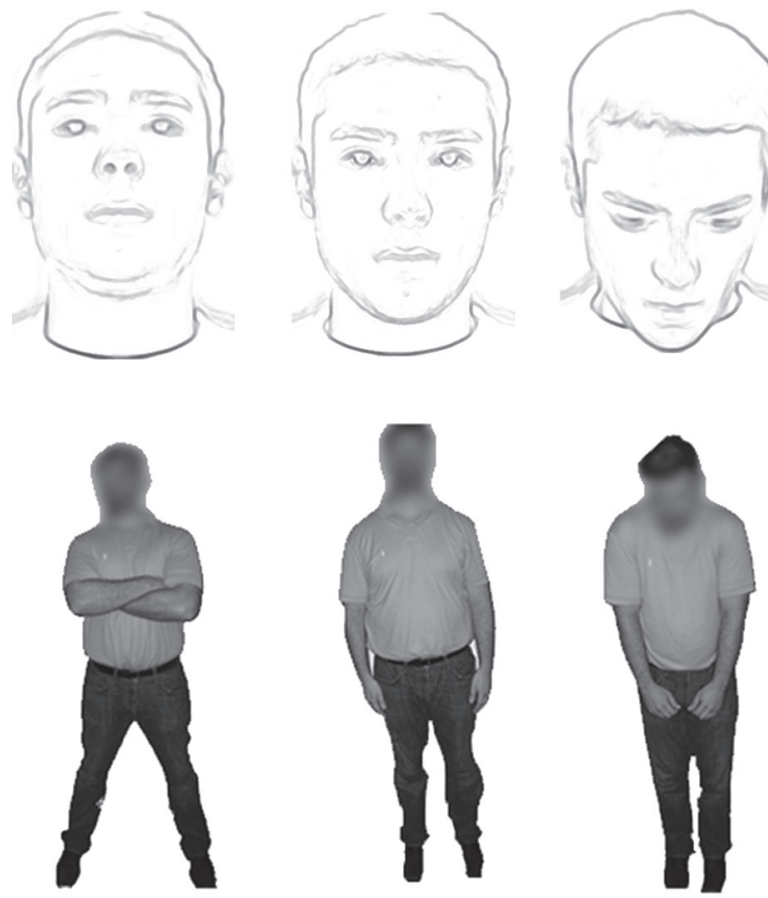

(a)
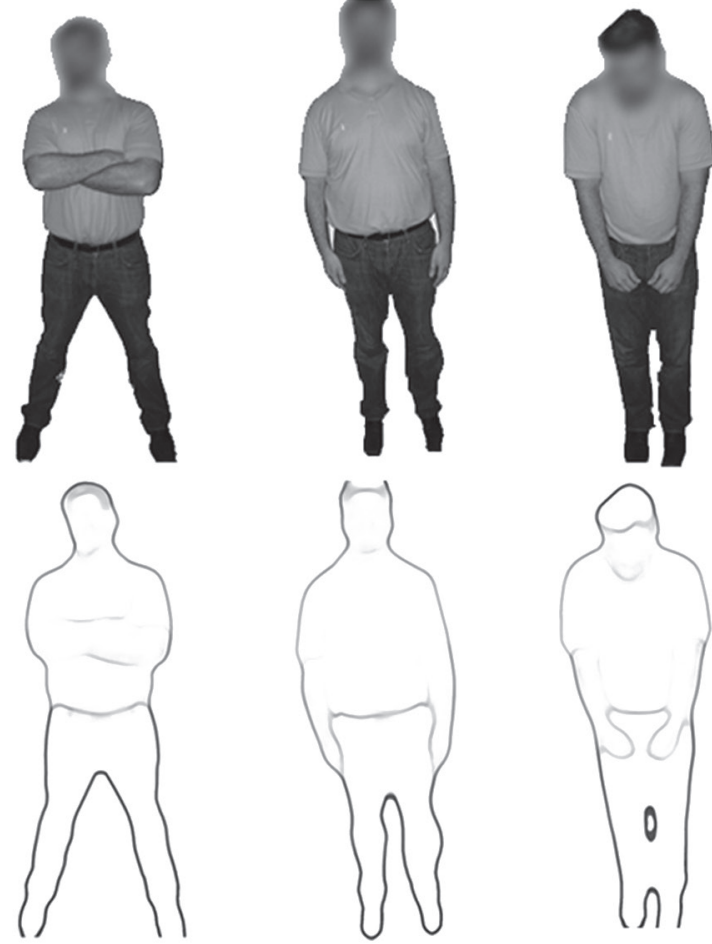

(b)

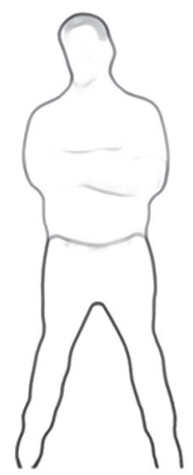

Dominant

Neutral

Submissive

Figure 1. Examples of dominant, neutral, and submissive face and body stimuli used in studies 1a, 1b, $2 \mathrm{a}$, and $2 \mathrm{~b}$, respectively.

\subsection{Study 1a. Results and discussion}

Participants' ratings of the faces were analyzed with sensitivity correlations (eg Judd et al 1991). Specifically, each participant's scores on the 8-point scale were correlated with a vector coded 1 for dominant stimuli, -1 for submissive stimuli, and 0 for neutral stimuli. The resulting correlation coefficient $(r)$ therefore provided an index of the individual participant's sensitivity to differences in the three poses. These $r$-values were then transformed to Fisher's $z$-scores for analysis. Descriptive statistics for the mean, raw ratings given to the stimuli are presented in table 1. 


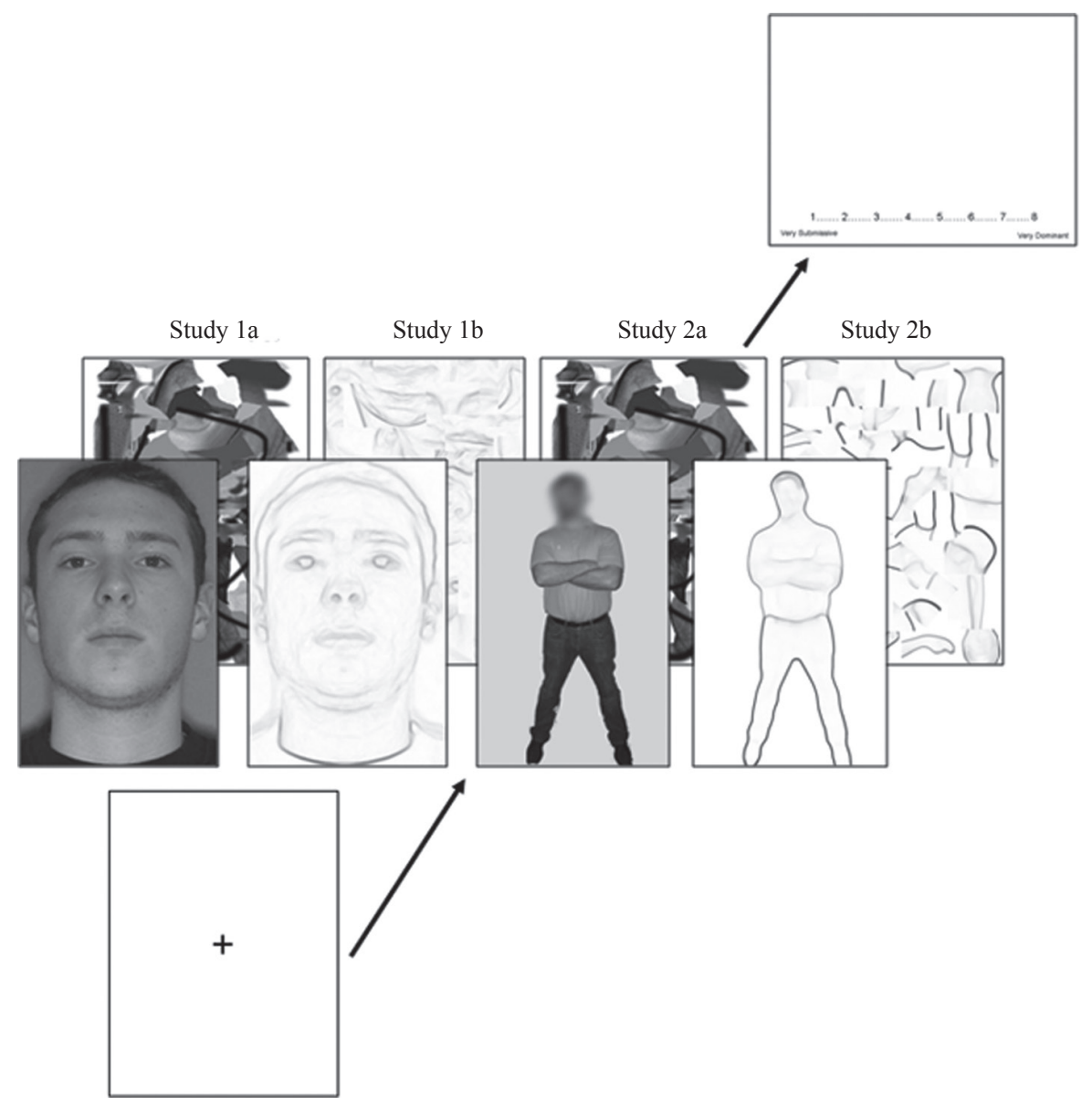

Figure 2. Illustration of procedures for the presentation of stimuli in the rapid presentation conditions in studies 1 and 2. Each trial began with the presentation of a fixation cross for $250 \mathrm{~ms}$, which was then succeeded by the target (in study 1, a face; in study 2, a body) for a condition-dependent duration (ie $27 \mathrm{~ms}, 40 \mathrm{~ms}$, or $94 \mathrm{~ms}$ ), which was immediately replaced by a $94 \mathrm{~ms}$ backward mask matched in spatial frequency distribution for the target stimulus class (ie face or body). Following the mask, participants were prompted to input their judgment of the target along an 8-point scale anchored at 1 (very submissive) and 8 (very dominant).

As illustrated in figure 3, the accuracy of inferring dominance and submission increased with more time to perceive the faces. Calculation of $95 \%$ confidence intervals for the mean Fisher-transformed sensitivity correlation in each condition permitted a test of the significance of participants' ability to infer dominance and submission at $\alpha=0.05$. These analyses showed that participants in the self-paced $(\sim 2000 \mathrm{~ms})$ condition, the $94 \mathrm{~ms}$ condition, and the $40 \mathrm{~ms}$ condition all perceived dominance and submission from the faces at levels significantly greater than chance (Fisher-transformed $r=0.00$ ). In contrast, participants in the $27 \mathrm{~ms}$ condition could not infer dominance and submission better than chance guessing.

Indeed, the results of a univariate ANOVA showed a significant main effect of time on participants' ability to detect dominance and submission from the face $\left(F_{3,60}=11.76\right.$, $\left.p<0.001, \eta_{\text {partial }}^{2}=0.37\right)$. Bonferroni-corrected $(\alpha=0.0083)$ pairwise contrasts between the conditions showed that participants' accuracy was significantly greater in the $40 \mathrm{~ms}$ $\left(t_{30}=4.02, p<0.001, r=0.59\right), 94 \mathrm{~ms}\left(t_{30}=5.57, p<0.001, r=0.71\right)$, and self-paced $\left(t_{30}=4.98, p<0.001, r=0.67\right)$ conditions than it was in the $27 \mathrm{~ms}$ condition. Participants in the $40 \mathrm{~ms}, 94 \mathrm{~ms}$, and self-paced conditions, however, did not significantly differ from one another in their levels of accuracy (all $t \mathrm{~s}<2.79$, all $p \mathrm{~s}>0.009$ ). 
Table 1. Means and standard errors for ratings given to stimuli in studies $1-3$ by study, stimulus condition, stimulus type, and exposure duration.

\begin{tabular}{|c|c|c|c|c|c|c|}
\hline \multirow[t]{2}{*}{ Study } & \multirow[t]{2}{*}{ Stimulus condition } & \multirow[t]{2}{*}{ Stimulus type } & \multicolumn{4}{|c|}{ Exposure duration condition } \\
\hline & & & $27 \mathrm{~ms}$ & $40 \mathrm{~ms}$ & $94 \mathrm{~ms}$ & Self-paced \\
\hline \multirow[t]{3}{*}{ Study 1a } & \multirow[t]{3}{*}{ full face } & dominant & $5.0(0.2)$ & $5.3(0.2)$ & $5.4(0.1)$ & $5.1(0.3)$ \\
\hline & & neutral & $5.1(0.2)$ & $5.0(0.1)$ & $4.5(0.1)$ & $4.0(0.1)$ \\
\hline & & submissive & $4.9(0.2)$ & $3.9(0.2)$ & $2.9(0.3)$ & $2.6(0.2)$ \\
\hline \multirow[t]{3}{*}{ Study 1b } & \multirow[t]{3}{*}{ outline face } & dominant & $5.3(0.3)$ & $5.0(0.3)$ & $5.7(0.2)$ & $5.5(0.2)$ \\
\hline & & neutral & $5.4(0.2)$ & $4.9(0.3)$ & $5.0(0.1)$ & $4.6(0.2)$ \\
\hline & & submissive & $5.3(0.3)$ & $3.4(0.3)$ & $3.3(0.4)$ & $2.9(0.3)$ \\
\hline \multirow[t]{3}{*}{ Study $2 \mathrm{a}$} & \multirow[t]{3}{*}{ full body } & dominant & $4.7(0.3)$ & $5.8(0.1)$ & $6.3(0.1)$ & $6.1(0.2)$ \\
\hline & & neutral & $4.7(0.2)$ & $4.8(0.1)$ & $4.1(0.1)$ & $4.0(0.2)$ \\
\hline & & submissive & $4.3(0.2)$ & $3.8(0.1)$ & $2.9(0.2)$ & $2.8(0.2)$ \\
\hline \multirow[t]{3}{*}{ Study $2 b$} & \multirow[t]{3}{*}{ outline body } & dominant & $5.2(0.2)$ & $5.7(0.3)$ & $5.9(0.2)$ & $6.1(0.2)$ \\
\hline & & neutral & $4.9(0.3)$ & $3.9(0.3)$ & $3.5(0.2)$ & $3.6(0.2)$ \\
\hline & & submissive & $5.1(0.2)$ & $3.5(0.3)$ & $2.1(0.1)$ & $1.8(0.1)$ \\
\hline \multirow[t]{12}{*}{ Study 2c } & \multirow[t]{3}{*}{ full body with head } & dominant & & & & $5.4(0.1)$ \\
\hline & & neutral & & & & $3.6(0.0)$ \\
\hline & & submissive & & & & $2.4(0.0)$ \\
\hline & \multirow[t]{3}{*}{ outline body with head } & dominant & & & & $5.8(0.0)$ \\
\hline & & neutral & & & & $3.2(0.1)$ \\
\hline & & submissive & & & & $2.9(0.1)$ \\
\hline & \multirow[t]{3}{*}{ full headless body } & dominant & & & & $5.5(0.1)$ \\
\hline & & neutral & & & & $3.2(0.0)$ \\
\hline & & submissive & & & & $1.8(0.0)$ \\
\hline & \multirow[t]{3}{*}{ outline headless body } & dominant & & & & $6.2(0.0)$ \\
\hline & & neutral & & & & $3.3(0.0)$ \\
\hline & & submissive & & & & $2.1(0.0)$ \\
\hline \multirow[t]{12}{*}{ Study 3} & \multirow[t]{3}{*}{ full face } & dominant & $5.2(0.1)$ & $5.7(0.1)$ & $5.9(0.1)$ & $5.3(0.1)$ \\
\hline & & neutral & $5.1(0.1)$ & $4.7(0.1)$ & $4.8(0.0)$ & $4.2(0.1)$ \\
\hline & & submissive & $4.7(0.1)$ & $3.3(0.1)$ & $2.9(0.1)$ & $2.2(0.1)$ \\
\hline & \multirow[t]{3}{*}{ outline face } & dominant & $5.1(0.1)$ & $5.5(0.1)$ & $5.7(0.1)$ & $5.2(0.1)$ \\
\hline & & neutral & $5.0(0.1)$ & $4.9(0.1)$ & $4.9(0.1)$ & $4.3(0.1)$ \\
\hline & & submissive & $5.0(0.1)$ & $3.9(0.1)$ & $3.0(0.0)$ & $2.4(0.1)$ \\
\hline & \multirow[t]{3}{*}{ full headless body } & dominant & $5.0(0.1)$ & $5.3(0.1)$ & $5.8(0.1)$ & $5.9(0.1)$ \\
\hline & & neutral & $5.0(0.1)$ & $4.3(0.1)$ & $3.9(0.1)$ & $3.5(0.1)$ \\
\hline & & submissive & $4.8(0.1)$ & $4.5(0.1)$ & $3.5(0.1)$ & $2.4(0.1)$ \\
\hline & \multirow[t]{3}{*}{ outline headless body } & dominant & $5.1(0.1)$ & $5.3(0.1)$ & $5.6(0.1)$ & $5.5(0.1)$ \\
\hline & & neutral & $5.1(0.1)$ & $4.4(0.1)$ & $3.6(0.1)$ & $3.4(0.1)$ \\
\hline & & submissive & $4.7(0.1)$ & $4.5(0.0)$ & $3.8(0.1)$ & $2.4(0.0)$ \\
\hline
\end{tabular}

In addition, we tested participants' response latencies across the four conditions. For all response latency analyses reported in this work, we calculated the mean latency for each participant's categorizations and transformed the data using the natural logarithm to achieve normality. We then submitted the transformed scores to a between-subjects univariate ANOVA, which showed a significant effect of time $\left(F_{3,60}=9.94, p<0.001, \eta_{\text {partial }}^{2}=0.33\right)$. Bonferroni-corrected $(\alpha=0.0083)$ pairwise contrasts between the conditions showed mixed effects: participants in the self-paced condition took significantly more time to respond than 


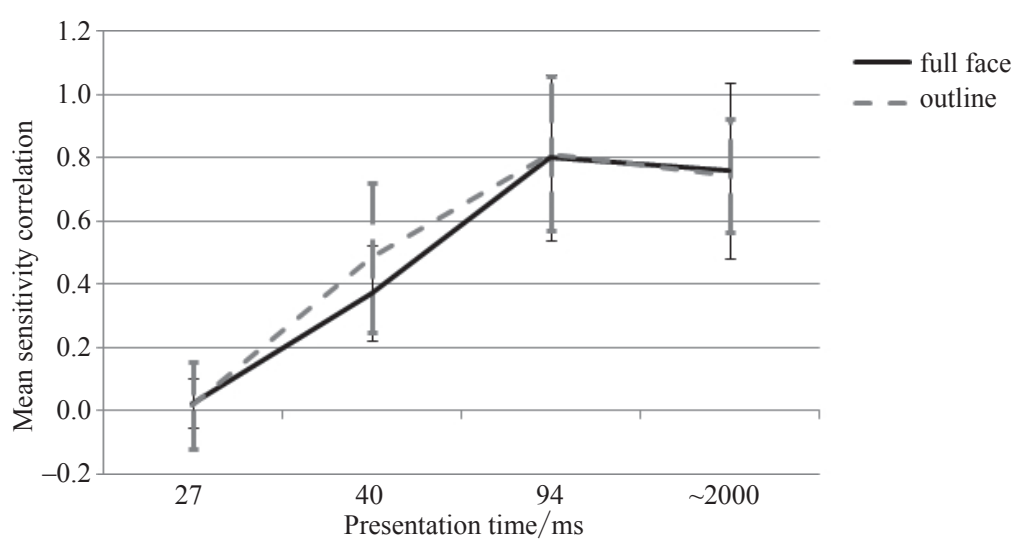

Figure 3. Accuracy results for the judgments of dominance from faces and outlines of faces across target presentation durations in study 1 . Scores represent mean Fisher-transformed sensitivity correlations in each condition and error bars display the $95 \%$ confidence intervals for each mean.

did participants in the $27 \mathrm{~ms}\left(t_{30}=3.58, p=0.001, r=0.55\right)$ and $40 \mathrm{~ms}\left(t_{30}=5.61, p<0.001\right.$, $r=0.72)$ conditions but did not differ from the participants in the $94 \mathrm{~ms}$ condition $\left(t_{30}=1.77\right.$, $p=0.09$ ). None of the other comparisons was significant following Bonferroni-correction $(t \mathrm{~s}<2.53, p \mathrm{~s}>0.02)$, with the exception of the comparison between the $40 \mathrm{~ms}$ and $94 \mathrm{~ms}$ conditions $\left(t_{30}=4.42, p<0.001, r=0.63\right)$. Although this pattern of effects is difficult to interpret, the means showed a general tendency to increase with additional viewing time (see figure 4). To test this, we constructed a linear contrast by coding each participant's score by condition ( $\lambda \mathrm{s}-2,-1,1$, and 2 , respectively) and correlated this with their transformed response latencies, yielding a significant effect $\left(r_{62}=0.58, p<0.001\right)$.

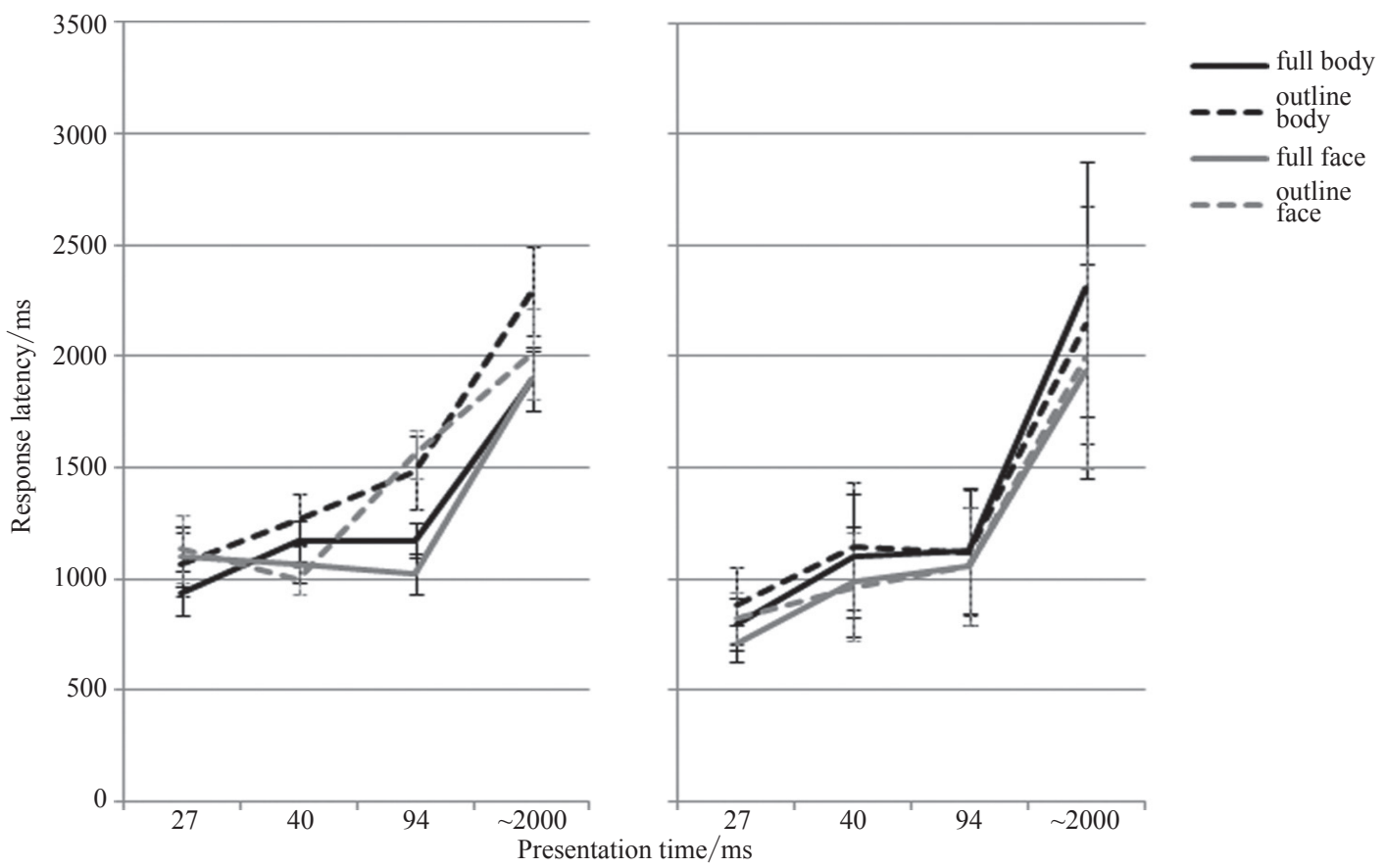

Figure 4. Mean untransformed response latencies for the four stimuli conditions in studies 1 and 2 (left panel) and study 3 (right panel). Error bars represent standard errors of the means. 
This difference suggests that participants might have been processing the stimuli longer when they were allowed more time to view them, as expected. Consistent with a speedaccuracy tradeoff (eg Wickelgren 1977), participants' accuracy was significantly correlated with their individual mean response latencies when the data were aggregated across conditions $\left(r_{62}=0.44, p<0.001\right)$. However, accuracy still significantly varied across conditions when controlling for response latency in a partial correlation $\left(r_{61}=0.41, p=0.001\right)$, suggesting that response time did not wholly explain participants' accuracy. In fact, response latency and accuracy were not significantly related when controlling for condition $\left(r_{61}=0.17, p=0.19\right)$. Moreover, given that the constraints on viewing time did not constrain the amount of time that participants were given to make their judgments, it may also be possible that the increased rapidity of the experiment paced the participants' judgments to be faster. That is, quicker stimulus presentations may encourage hypervigilance among perceivers, heightening their anticipation of the forthcoming stimuli and reducing their response latencies.

Thus, participants accurately judged the level of dominance expressed by a posed face when seeing it as briefly as $40 \mathrm{~ms}$. Briefer presentations (ie $27 \mathrm{~ms}$ ) did not allow for an accurate assessment of dominance/submission from the face. Participants with more than $40 \mathrm{~ms}$ of time to view the faces, including those with unlimited time (ie the self-paced condition), showed no significant increase in accuracy with greater time. Thus, participants' accuracy at $40 \mathrm{~ms}$ was not significantly different from their accuracy when given unlimited viewing time. Expressions of dominance and submission from facial cues therefore provided a rather strong and reliable signal that was accurately perceived with only $1 / 25$ th of a second exposure to a face. Study $1 \mathrm{~b}$ explored these same judgments under additional constraints, as the face stimuli were impoverished to remove all but the major contours of the face and its features.

\subsection{Study 1b. Method}

Sixty-four undergraduates participated for partial credit in an introductory psychology course. Equal numbers of participants $(n=16)$ were randomly assigned to four presentationtime conditions: $27 \mathrm{~ms}$ exposure, $40 \mathrm{~ms}$ exposure, $94 \mathrm{~ms}$ exposure, or self-paced exposure $(M=2291 \mathrm{~ms}, \mathrm{SE}=197 \mathrm{~ms})$.

The stimuli and procedures were the same as in study 1a (ie 60 trials total) but with an important difference. Each photo was processed to remove many of the facial details, resulting in an outline of the face and its major features (see figure 1). In turn, a suitable backward mask was constructed by scrambling sections of the facial outline stimuli (eg figure 2). Thus, we aimed to measure sensitivity to dominance cues when the stimuli were impoverished to remove details of the face.

\subsection{Study 1b. Results and discussion}

Perceptions of dominance from facial outlines were similar to those of the full faces. Participants' accuracy generally increased as they were given more time to view the stimuli (see figure 3 ). The mean sensitivity correlations were bounded by $95 \%$ confidence intervals that did not contain 0 (ie significant at $\alpha=0.05$ ) for each of the $40 \mathrm{~ms}, 94 \mathrm{~ms}$, and self-paced ( $\sim 2300 \mathrm{~ms}$ ) conditions - but not for the $27 \mathrm{~ms}$ exposure condition. Thus, perceivers viewing facial outlines for $40 \mathrm{~ms}$ and greater were significantly better than chance in their judgments of dominance and submission (see also table 1 for descriptive statistics).

Participants' accuracy significantly varied by condition. A between-subjects univariate ANOVA of the participants' individual sensitivity correlations showed a significant effect $\left(F_{3,60}=12.04, p<0.001, \eta_{\text {partial }}^{2}=0.38\right)$. Pairwise, Bonferroni-corrected $(\alpha=0.0083)$ contrasts revealed that the accuracy of judgments in the $40 \mathrm{~ms}\left(t_{30}=3.37, p=0.002, r=0.52\right), 94 \mathrm{~ms}$ $\left(t_{30}=5.58, p<0.001, r=0.71\right)$, and self-paced $\left(t_{30}=6.32, p<0.001, r=0.76\right)$ conditions was significantly greater than in the $27 \mathrm{~ms}$ condition; however accuracy in these three conditions did not significantly differ (all $t \mathrm{~s}<1.89$, all $p \mathrm{~s}>0.07$ ). 
Natural-logarithm transformed response latencies also differed by condition $\left(F_{3,60}=12.34\right.$, $p<0.001, \eta_{\text {partial }}^{2}=0.38$ ). Following the results of study $1 \mathrm{a}$, we conducted an a priori linear contrast corresponding to exposure time, which yielded a significant effect $\left(t_{60}=5.74\right.$, $p<0.001, r=0.60$; see figure 4). However, Bonferroni-corrected $(\alpha=0.0083)$ pairwise comparisons showed that this effect was driven primarily by increased response latencies for the self-paced condition against the speeded conditions (all $t \mathrm{~s}>3.71$, all $p \mathrm{~s}<0.001$, all $r \mathrm{~s}>0.56$ ), which did not significantly differ from one another following Bonferronicorrection (all $t \mathrm{~s}<2.39$, all $p \mathrm{~s}>0.02$ ). Although it is inconsistent with the findings of study $1 \mathrm{a}$, it is not entirely surprising that participants in the self-paced condition would take longer to respond to the stimuli, since their response latency scores reflect both their decision time (as in the speeded duration conditions) as well as their viewing time (in contrast to only the latter in the speeded duration conditions). Accuracy and response latency were significantly correlated $\left(r_{62}=0.35, p=0.005\right)$ but, as above, this relationship was not significant when controlling for condition $\left(r_{61}=0.04, p=0.77\right)$.

Dominance can therefore be accurately detected from facial cues both when perceivers view full faces and when they view just outlines of the major facial features. Presentations that are relatively subliminal (ie $27 \mathrm{~ms}$, backward-masked exposures) do not provide sufficient information for accurate judgments, but judgments with greater exposure time (40 ms and beyond) do provide sufficient time to extract information about dominance and submission. Study 2 investigates this further by measuring the accuracy of perceptions of dominance from bodily cues.

\section{Study 2}

Study 1 showed that dominance could be accurately judged from facial cues that were perceived for $40 \mathrm{~ms}$ or longer. To further investigate the perception of dominance and submission from nonverbal cues, in study2 we examined the accuracy of judgments of dominance and submission from posed body postures at the same brief exposure times. Consistent with previous work indicating the importance of body posture in communicating dominance and submission among humans and non-human animals (eg Freeman et al 2009; Hall et al 2005; Mazur 2005), we expected that cues to dominance and submission from bodies would also yield strong effects. We again tested these effects using both full photos (study 2a) and figural outlines (study 2b). Finally, we tested the role that the combination of head and face information contributed to these effects in study $2 \mathrm{c}$.

\subsection{Study 2a. Method}

3.1.1 Participants. Sixty-five undergraduates participated for partial credit in an introductory psychology course or for monetary compensation. Approximately equal numbers of participants were randomly assigned to one of four conditions based on presentation time: $27 \mathrm{~ms}$ exposure $(n=15), 40 \mathrm{~ms}$ exposure $(n=16), 94 \mathrm{~ms}$ exposure $(n=17)$, or self-paced exposure $(n=17)$. One participant was excluded from analysis because he gave the same rating to all of the stimuli.

3.1.2 Stimuli. Six Caucasian male actors enacted three different bodily poses of dominance, submission, and neutrality, for a total of 9 poses per target and 54 stimuli in total. Hall et al (2005) provided a detailed meta-analysis of the specific cues relating to perceptions of dominance in interactions. One of the key variables highlighted in this work that is also available from static images is the way an individual occupies space. Generally, expressions of dominance tend to occupy larger amounts of physical space whereas expressions of submission tend to occupy smaller amounts of physical space (eg Carney et al 2005). 
Thus, both openness and expansiveness are related to expressions of dominance and power (Carney et al 2010). Not all open postures necessarily connote dominance, however. For example, an individual lying in the snow with limbs stretched out to make a snow angel would not be perceived as especially dominant; nor would an individual performing jumping jacks aerobics, although these activities would maximize the amount of space an individual might occupy. In contrast, some positions that might seem contractive-such as crossing one's arms across one's chest accompanied by an arched back - actually increase the size of the shoulders and chest. Indeed, past work has shown that figures with wider shoulders are perceived as more masculine (Johnson et al 2007) and that masculinity is correlated with perceptions of dominance (eg Rule and Ambady 2009). Thus, posing in a way that makes one's shoulders and chest look larger may lead to higher ratings of dominance.

The expansive and contractive qualities of expressions of dominance and submission, respectively, were particularly influential in the creation of bodily cues to dominance in the current stimuli. To express dominance, targets were asked to pose (i) with back arched, arms crossed across the chest, and legs spread wide; (ii) with legs spread wide and akimbo arms placed on the hips; and (iii) with legs spread wide, shoulders tilted forward, and arms spread aggressively. To express submission, we asked targets to pose (i) turned away with feet close together, shoulders hunched, and looking back over their shoulder at the camera; (ii) with feet close together, shoulders hunched, and arms crossed, shot in profile view; and (iii) with feet close together, shoulders hunched and rolled forward, arms held close against the sides of the body, and hands placed in front of the pelvis. Finally, neutral poses consisted of two photos of targets standing casually with arms hanging down along the sides of the body comfortably, and one photo standing with hands joined casually in front of the body (see figure 1 for examples). The targets were photographed under conditions standardized for lighting, camera angle, distance from camera, and background. We then blurred the faces in an attempt to prevent the possibility of compound or conflicting face and body cues and standardized them to be roughly equal in size (all stimuli subtended between $13.02 \mathrm{deg}$ and $17.76 \mathrm{deg}$ of visual angle).

3.1.3 Procedure. Participants were instructed that they would be seeing a series of bodies appear on the computer screen and that they would be rating them along a scale from 1 (very submissive) to 8 (very dominant). Participants in the self-paced condition then began rating the stimuli, which appeared in a random order, for a total of 54 trials (ie one trial per stimulus: 18 for dominant bodies, 18 for neutral bodies, and 18 for submissive bodies). Participants in the time-limited conditions, however, were given three practice trials to orient them with the timing of the task. As in study 1, they were further instructed that they would see a series of images before making their judgment about the body: a fixation cross (to cue attention), the target body, a piece of "abstract art" (a backward mask matched for high and low spatial frequencies), and finally the screen prompting them for their rating of the body (see figure 2). Participants in all conditions were instructed to work as quickly and accurately as possible. Analysis of participants' response latencies indicated that the mean presentation time for faces in the self-paced condition was $1886 \mathrm{~ms}(\mathrm{SE}=125 \mathrm{~ms})$.

\subsection{Study 2a. Results and discussion}

Participants' ratings of the bodies were analyzed with sensitivity correlations, as above, correlating each participant's scores on the 8-point scale with a vector coded 1 for dominant stimuli, -1 for submissive stimuli, and 0 for neutral stimuli. Descriptive statistics for the ratings of the stimuli are presented in table 1.

As illustrated in figure 5, the accuracy of inferring dominance and submission increased with more time to perceive the bodies. Calculation of $95 \%$ confidence intervals for the mean Fisher-transformed sensitivity correlation in each condition permitted a test of the significance 


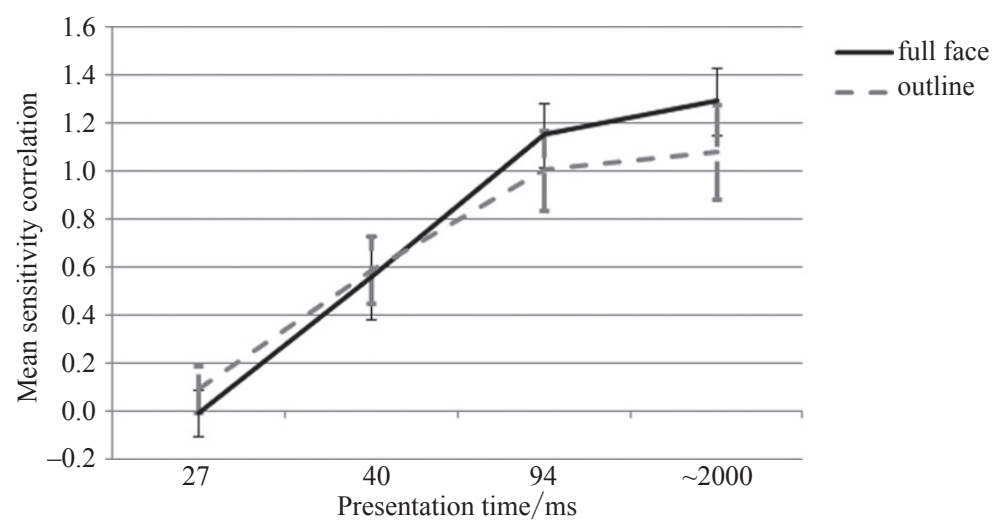

Figure 5. Accuracy results for the judgments of dominance from bodies and figural outlines of bodies across target presentation durations in studies $2 \mathrm{a}$ and $2 \mathrm{~b}$. Scores represent mean Fisher-transformed sensitivity correlations in each condition, and error bars display the $95 \%$ confidence intervals for each mean.

of participants' ability to infer dominance and submission at $\alpha=0.05$. These analyses showed that participants in the self-paced ( 1900 ms) condition, the $94 \mathrm{~ms}$ condition, and the $40 \mathrm{~ms}$ condition perceived dominance and submission from the bodies at levels significantly greater than chance. In contrast, participants in the $27 \mathrm{~ms}$ condition could not infer dominance and submission better than chance guessing (ie $r=0.00$ ).

Indeed, the results of a univariate ANOVA showed a significant main effect of time on participants' ability to detect dominance and submission from the bodies $\left(F_{3,60}=64.12\right.$, $\left.p<0.001, \eta_{\text {partial }}^{2}=0.76\right)$. Bonferroni-corrected $(\alpha=0.0083)$ pairwise contrasts between the conditions showed that participants' accuracy was significantly greater in the $40 \mathrm{~ms}$ $\left(t_{28}=5.33, p<0.001, r=0.71\right), 94 \mathrm{~ms}\left(t_{29}=13.01, p<0.001, r=0.92\right)$, and self-paced $\left(t_{29}=13.94, p<0.001, r=0.93\right)$ conditions than it was in the $27 \mathrm{~ms}$ condition. Similarly, participants in the $94 \mathrm{~ms}\left(t_{31}=4.15, p<0.001, r=0.60\right)$ and self-paced $\left(t_{31}=6.45, p<0.001\right.$, $r=0.76$ ) conditions were significantly more accurate than in the $40 \mathrm{~ms}$ condition. However, participants in the $94 \mathrm{~ms}$ and self-paced conditions did not significantly differ from one another in their levels of accuracy $\left(t_{32}=1.40, p=0.17\right)$.

As with the faces in study 1 , natural-logarithm transformed response latencies varied by condition for judgments of the bodies here as well $\left(F_{3,60}=13.70, p<0.001, \eta_{\text {partial }}^{2}=0.41\right)$. Again, a linear contrast showed that response latency significantly increased as a function of increasing stimulus exposure time $\left(t_{60}=5.61, p<0.001, r=0.59\right)$. As in study $1 \mathrm{~b}$, however, this was driven by significant differences between the speeded versus self-paced conditions (all $t \mathrm{~s}>4.40$, all $p \mathrm{~s}<0.001$, all $r \mathrm{~s}>0.62$ ), the former of which did not differ from one another following Bonferroni-correction $(\alpha=0.0083$; all $t \mathrm{~s}<2.20$, all $p \mathrm{~s}<0.04)$. Once again, the relationship between accuracy and response latency was significant $\left(r_{62}=0.51\right.$, $p<0.001)$ but not when accounting for condition $\left(r_{61}=0.08, p=0.53\right.$; see figure 4$)$.

Thus, participants accurately judged the level of dominance displayed by a posed body when seeing it for as little as $40 \mathrm{~ms}$. Briefer presentations (ie $27 \mathrm{~ms}$ ) did not allow for accurate assessments but participants were significantly more accurate when viewing the bodies for $94 \mathrm{~ms}$ or longer than they were when viewing the bodies for $40 \mathrm{~ms}$. Although participants' mean accuracy scores were the highest for judgments made at a self-paced duration, selfpaced accuracy did not significantly differ from the accuracy observed following only $94 \mathrm{~ms}$ presentations. We therefore observed no advantage in accuracy for perceiving targets for more than approximately $1 / 10$ th of a second, with about $1 / 25$ th of a second being the critical threshold at which accurate judgments could be made. 


\subsection{Study 2b. Method}

Similar to study $1 \mathrm{~b}$, each photo was processed with image-editing software to create a figural outline, showing only the major contours of the targets' bodies. The goal of this processing was to control for variations in color, clothing, and targets' facial expressions, permitting a well-standardized set of targets who effectively depicted dominance, submission, and neutrality signals (see figure 1 for examples). Sixty-four undergraduates ( $n=16$ per time exposure condition: $27 \mathrm{~ms}, 40 \mathrm{~ms}, 94 \mathrm{~ms}$, and self-paced) followed the same procedures as in study 2 a (ie 54 trials in total). A suitable backward mask was created by scrambling the figural outline images. Mean response latency in the self-paced condition was $2574 \mathrm{~ms}$ $(\mathrm{SE}=197 \mathrm{~ms})$.

\subsection{Study 2b. Results and discussion}

Data were analyzed with sensitivity correlations, as above (see also table 1). Accuracy was significantly greater than chance in each of the $40 \mathrm{~ms}, 94 \mathrm{~ms}$, and self-paced conditions. Judgments made with only $27 \mathrm{~ms}$ of exposure time were not significant, however, as the $95 \%$ confidence interval contained 0. A univariate ANOVA comparing the participants' accuracy across time conditions showed a significant difference $\left(F_{3,60}=33.26, p<0.001, \eta_{\text {partial }}^{2}=0.62\right)$. Bonferroni-corrected $(\alpha=0.0083)$ simple effects $t$-tests indicated that participants' accuracy in the $27 \mathrm{~ms}$ condition significantly differed from the accuracy of participants in the $40 \mathrm{~ms}$ $\left(t_{30}=5.61, p<0.001, r=0.72\right), 94 \mathrm{~ms}\left(t_{30}=9.29, p<0.001, r=0.86\right)$, and self-paced $\left(\sim 2600 \mathrm{~ms} ; t_{30}=8.91, p<0.001, r=0.85\right)$ conditions - and that accuracy in the $94 \mathrm{~ms}$ $\left(t_{30}=3.72, p<0.001, r=0.56\right)$ and self-paced $\left(t_{30}=4.00, p<0.001, r=0.59\right)$ conditions was significantly greater than accuracy in the $40 \mathrm{~ms}$ condition. Accuracy did not differ between the $94 \mathrm{~ms}$ and self-paced conditions, however $\left(t_{30}=0.58, p=0.56\right.$; see figure 5).

Analysis of the natural-logarithm transformed response latencies continued to show a significant difference according to exposure time condition $\left(F_{3,60}=9.24, p<0.001\right.$, $\eta_{\text {partial }}^{2}=0.32$; see figure 4$)$. Response latencies again increased linearly with greater stimulus exposure time $\left(t_{60}=3.74, p<0.001, r=0.43\right)$, but this was mostly due to differences between the speeded-duration versus self-paced conditions (all $t \mathrm{~s}>4.11$, all $p \mathrm{~s}<0.001$, all $r \mathrm{~s}>0.60)$, as none of the speeded conditions differed from one another following Bonferronicorrection $(\alpha=0.0083)$ : all $t \mathrm{~s}<0.31$, all $p \mathrm{~s}>0.76$. Although accuracy and response latency were significantly correlated $\left(r_{62}=0.39, p=0.001\right)$, this relationship was once again nonsignificant when accounting for exposure condition $\left(r_{61}=0.15, p=0.26\right)$.

\subsection{Study $2 c$}

One limitation of studies $2 \mathrm{a}$ and $2 \mathrm{~b}$ is that the heads were still present upon the bodies. Although the information from heads and faces was blurred to obscure any signals they might provide, the head's vertical orientation might have still been sufficiently visible as to increase the signal from the stimulus overall. In study $2 \mathrm{c}$, we tested this directly by cropping the heads from the full photos and outlines of the bodies and compared these to ratings of dominance given to the bodies used in studies $2 \mathrm{a}$ and $2 \mathrm{~b}$.

3.5.1 Study 2c. Method. Eighty-two participants from Amazon's Mechanical Turk online community (see Buhrmester et al 2011) were randomly assigned to rate either full bodies with blurred heads (as in study $2 \mathrm{a} ; n=22$ ), outline bodies with blurred heads (as in study $2 \mathrm{~b} ; n=20)$, full bodies with heads removed $(n=19)$, or outline bodies with heads removed $(n=21)$. The procedures were the same as in the above studies (ie 54 trials in total), except that participants were tested only in the self-paced condition and information about response latency was not obtained. 
3.5.2 Study 2c. Results and discussion. Participants' responses were again analyzed with sensitivity correlations, and the mean responses are presented in table 1 . None of the $95 \%$ confidence intervals surrounding the Fisher-transformed means contained 0 (see figure 6). More pertinent to the purpose of the experiment, we conducted a 2 (figure type: head or no head) $\times 2$ (stimulus type: full or outline) between-subjects ANOVA on the Fisher-transformed sensitivity correlations. Results revealed a main effect of figure type $\left(F_{1,78}=15.49, p<0.001\right.$, $r=0.41)$, in which bodies with heads $(M=1.18, \mathrm{SE}=0.06)$ were rated significantly more accurately than bodies without heads $(M=0.85, \mathrm{SE}=0.06)$; no other effects were significant $(F \mathrm{~s}<0.70, p \mathrm{~s}>0.41)$. Simple effects tests showed that this was true among the comparisons for both the full $\left(t_{39}=2.15, p=0.038, r=0.33\right)$ and outline $\left(t_{41}=3.42, p<0.001, r=0.47\right)$ bodies, though the former did not survive Bonferroni correction $(\alpha=0.025)$.

The head therefore adds information about dominance that increases judgmental accuracy, at least for self-paced judgments. This is consistent with previous work in emotion recognition, which showed that the combination of faces and bodies were judged more accurately than either alone (de Gelder and Tamietto 2011; Meeren et al 2005). The accuracy of judgments from the full and outline bodies in studies $2 \mathrm{a}$ and $2 \mathrm{~b}$, respectively, might have therefore been enhanced by the combination of information from the body and head. Study 3 explores the relative accuracy of dominance judgments from the head and body further by comparing judgments of the face and body (without heads) in a single, within-subjects design.

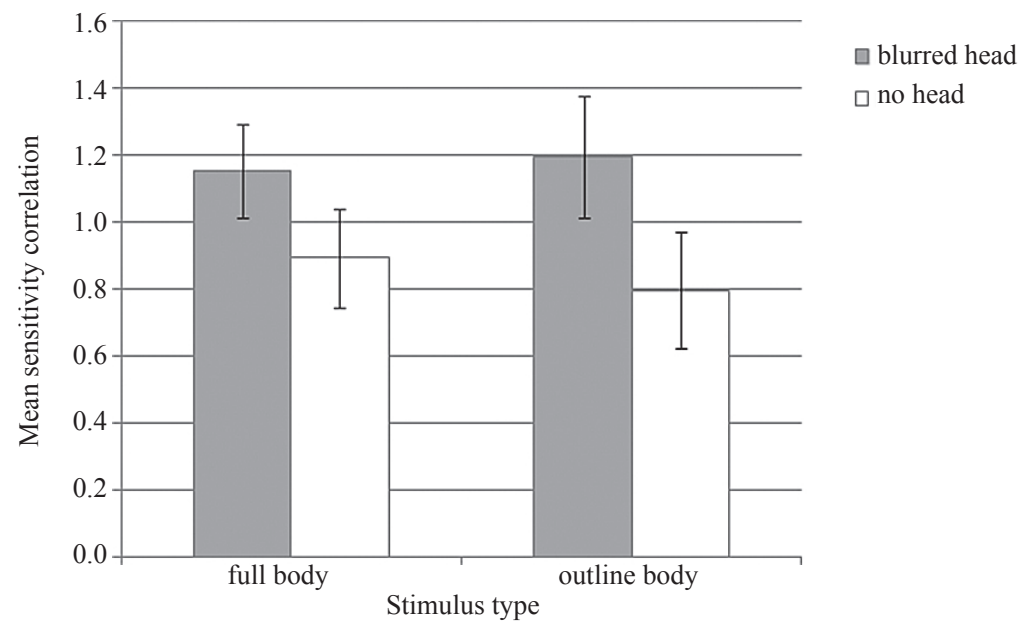

Figure 6. Accuracy results for the judgments of full and outline bodies with and without heads in study 2c. Scores represent the mean Fisher-transformed sensitivity correlations in each condition, and error bars display the $95 \%$ confidence intervals for each mean.

\section{Study 3}

The results of studies 1 and 2 showed that dominance could be judged from posed faces and bodies with accuracy that was significantly greater than chance guessing, even when these stimuli were impoverished to include only the major high spatial frequency information in the images. Observation of the means from these studies suggests that the effects may differ between the different types of stimuli (faces, bodies, full spectrum, outlines), however. Study 3 therefore sought to test the judgments of faces and bodies (both full spectrum and outlines) within a single design that would allow for direct comparisons of the different types of stimuli. 


\subsection{Study 3. Method}

Sixty-four undergraduates viewed all of the stimuli from studies 1 and 2 in a 2 (stimulus focus: body or face) $\times 2$ (stimulus type: full or outline) $\times 4$ (exposure duration: $27 \mathrm{~ms}, 40 \mathrm{~ms}$, $94 \mathrm{~ms}$, or self-paced) design with repeated measures on the first two factors. Equal numbers of participants $(n=16)$ were randomly assigned to each of the exposure duration conditions. The four types of stimuli were presented in a fully randomized order (ie 228 trials: 60 full faces, 60 outline faces, 54 full bodies, 54 outline bodies) and succeeded by the backward mask used in study 1. Rather than blur the faces on the bodies, we cropped the heads from the images entirely, as in study $2 \mathrm{c}$. As above, participants rated each target's dominance along the same 8-point scale. Mean response latency in the self-paced condition was $2141 \mathrm{~ms}$ $(\mathrm{SE}=156 \mathrm{~ms})$.

\subsection{Study 3. Results and discussion}

We first calculated sensitivity correlations with $95 \%$ confidence intervals, as above (but see table 1 for descriptive statistics of initial ratings). Accuracy was greater than chance in all conditions except for the judgments of all four stimulus types presented for $27 \mathrm{~ms}$. The Fisher-transformed sensitivity correlations were then submitted to a 2 (stimulus focus) $\times 2$ (stimulus type) $\times 4$ (exposure duration) repeated-measures ANOVA with exposure duration entered as a between-subjects variable. This revealed significant main effects of stimulus focus and stimulus type. Overall, the face was judged significantly more accurately than the body $\left(F_{1,60}=21.57, p<0.001, r=0.51\right)$, and the full stimuli were judged significantly more accurately than the impoverished outline stimuli $\left(F_{1,60}=20.28, p<0.001, r=0.50\right)$.

As above, we also observed a main effect of time $\left(F_{3,60}=23.01, p<0.001, \eta_{\text {partial }}^{2}=0.54\right)$, and Bonferroni-corrected $(\alpha=0.0083) t$-tests again showed significant differences between all conditions except the comparison between the $94 \mathrm{~ms}$ and self-paced $(\sim 2100 \mathrm{~ms})$ conditions $\left(t_{30}=1.87, p=0.07\right)$. This main effect of time was qualified by an interaction with stimulus focus, however $\left(F_{3,60}=6.33, p=0.001, \eta_{\text {partial }}^{2}=0.24\right)$. This effect is visible in figure 7 , which shows that accuracy increases more quickly for judgments from faces than bodies, with faces being significantly (Bonferroni-corrected $\alpha=0.0125$ ) more accurate than bodies at $40 \mathrm{~ms}$ $\left(t_{15}=3.23, p=0.006, r=0.64\right)$ and $94 \mathrm{~ms}\left(t_{15}=3.83, p=0.002, r=0.70\right)$, but not at either $27 \mathrm{~ms}$ or self-paced $(t \mathrm{~s}<0.59, p \mathrm{~s}>0.55)$ durations. These differences in rates of change among the bodies and faces were supported by a non-significant difference between the $27 \mathrm{~ms}$ and $40 \mathrm{~ms}$ conditions for judgments of the bodies (Bonferroni-corrected $\alpha=0.0042 ; t_{30}=1.99$, $p=0.06)$ that was significant for judgments of the faces $\left(t_{30}=3.32, p=0.002, r=0.52\right)$ and

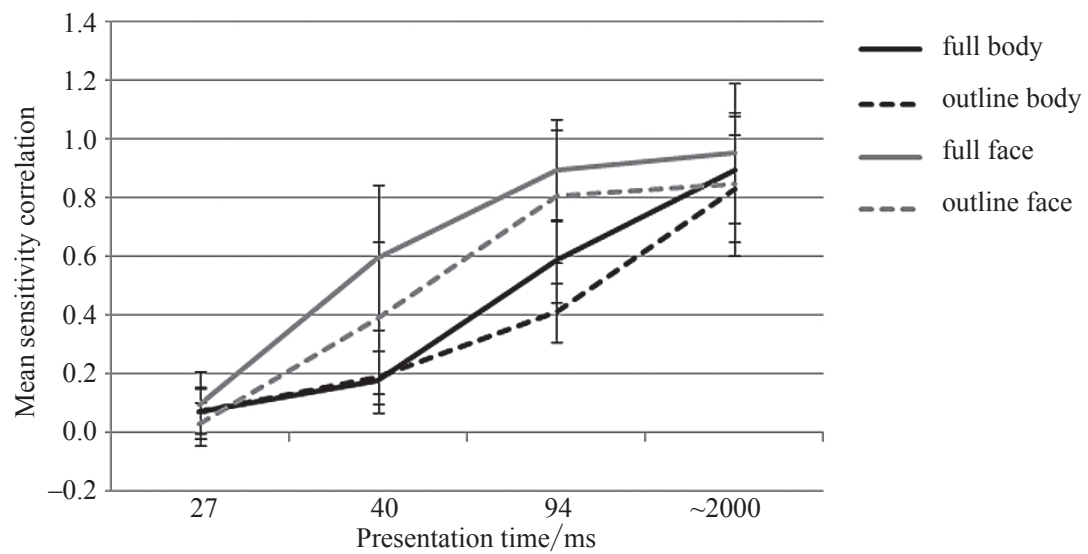

Figure 7. Accuracy results for the judgments of full and outline bodies and faces in study 3. Scores represent the mean Fisher-transformed sensitivity correlations in each condition, and error bars display the $95 \%$ confidence intervals for each mean. 
a significant difference between the $94 \mathrm{~ms}$ and self-paced conditions for judgments of the bodies $\left(t_{30}=3.47, p=0.002, r=0.53\right)$ that was non-significant for judgments of the faces $\left(t_{30}=0.28, p=0.78\right)$. This effect was further qualified by a 3 -way interaction with stimulus type $\left(F_{3,60}=3.21, p=0.03, \eta_{\text {partial }}^{2}=0.14\right)$, which was driven primarily by large increases in the accuracy of full bodies over body outlines in the $94 \mathrm{~ms}$ condition, and of full faces over face outlines in the $40 \mathrm{~ms}$ conditions; however, none of the simple effects reached significance following Bonferroni-correction ( $\alpha=0.0042$; all $t \mathrm{~s}<3.02$, all $p \mathrm{~s}>0.009)$.

We conducted a similar 2 (stimulus focus) $\times 2$ (stimulus type) $\times 4$ (exposure duration) repeated-measures ANOVA with exposure duration entered as a between-subjects variable on the participants' natural-logarithm-transformed response latencies. Results revealed a main effect of stimulus focus, whereby faces (untransformed $M=1193 \mathrm{~ms}, \mathrm{SE}=68 \mathrm{~ms}$ ) were rated significantly faster than bodies (untransformed $M=1328 \mathrm{~ms}, \mathrm{SE}=78 \mathrm{~ms} ; F_{1,60}=8.90$, $p=0.004, r=0.36)$. They also showed the now familiar main effect of exposure time $\left(F_{3,60}=14.54, p<0.001, \eta_{\text {partial }}^{2}=0.41\right)$. No other effects reached significance (all $F \mathrm{~s}<0.95$, all $p \mathrm{~s}>0.42$ ), though the stimulus type $\times$ condition interaction was marginally significant $\left(F_{3,60}=2.56, p=0.06, \eta_{\text {partial }}^{2}=0.11\right)$. A linear contrast of the mean response latencies for all conditions again showed a linear increase with greater exposure duration $\left(t_{60}=5.97\right.$, $p<0.001, r=0.63$; see figure 4). Bonferroni-corrected $(\alpha=0.0083)$ pairwise comparisons showed that the speeded duration conditions all significantly differed from the self-paced condition (all $t \mathrm{~s}>4.35$, all $p \mathrm{~s}<0.001$, all $r \mathrm{~s}>0.62$ ) but not from one another (all $t \mathrm{~s}<2.59$, all $p \mathrm{~s}>0.01)$. This pattern was consistent when each stimulus condition was tested separately and the correction for multiple comparisons was further reduced $(\alpha=0.002)$. Moreover, as above, accuracy and response latency were significantly correlated for all four stimulus types (all $r \mathrm{~s}>0.41$, all $p \mathrm{~s}<0.001$ ), but these relationships became non-significant when accounting for condition (all $r \mathrm{~s}<0.22$, all $p \mathrm{~s}>0.09$ ).

The results of study 3 therefore reproduced those in studies 1 and 2: dominance was judged from all of posed faces, facial outlines, bodies, and body outlines at levels more accurate than chance guessing, and this accuracy increased with greater viewing time. In addition, study 3 allowed us to observe that faces were judged more accurately than were bodies, that full stimuli were judged better than were impoverished stimuli, and that these effects vary across time.

\section{General discussion}

The human face and body provide reliable signals of dominance and submission. Study 1 showed that participants could accurately discern dominance and submission from posed facial displays when observing a face presented as briefly as $40 \mathrm{~ms}$. Study 2 extended these findings to judgments of bodies. Participants again were able to accurately judge dominance and submission when perceiving a target for only $40 \mathrm{~ms}$. Moreover, in both studies, accuracy increased significantly in the conditions with greater time, and study 3 showed that accuracy was greater for perceptions based on the faces and when stimuli contained both high and low spatial frequency information. Consistent with the ecological theory of social perception (McArthur and Baron 1983; Zebrowitz and Collins 1997), these data suggest that a mere glimpse of just an outline of a face or body - as brief as $1 / 25$ th of a second - is all that is needed to accurately perceive the dominance and submission displayed by another person.

Importantly, participants were more accurate in their judgments based on the faces than they were in their judgments based on the bodies. Although the body exerts a pronounced importance for expressing cues to dominance (Hall et al 2005; Mazur 2005), the face is a uniquely rich resource for perceiving and expressing information about social behaviors, thoughts, and intentions (eg Rinn 1991; Zebrowitz 1997). Indeed, the face is a special stimulus, 
for humans, subserved by dedicated neural processing (Moscovitch et al 1997). Thus, although body motion presents proximal behavioral information (eg intentions in action), human targets and perceivers may preferentially rely on facial cues for information about dominance and submission. Moreover, targets may be more capable of expressing dominance through their faces than through their bodies. Notably, this may be distinct from non-human animals, for whom cues from the body (eg traits like size) are presumed to provide clearer and more reliable signals of dominance (eg Mazur 2005). Future work may therefore consider comparing dominance signals from the faces and bodies of non-human targets and perceivers.

The present work also builds on previous research that has examined the ability to perceive social cues under restricted conditions, such as speeded durations (eg Bar et al 2006; Rule and Ambady 2008; Rule et al 2009a). The present results extend this work by showing that accurate judgments can be made at speeded rates for perceptions of dominance. Whereas previous work has shown that dominance can be reliably judged from nonverbal cues (eg Mignault and Chaudhuri 2003; Schmid Mast and Hall 2004), the present studies extend these findings by showing that static faces and bodies express cues to dominance and submission that can be gleaned from very brief exposures. Moreover, this was true even when the stimuli were impoverished to only show outlines of major contours. These findings therefore provide support for an ecological framework of social perception by demonstrating that even very visually and temporally limited cues to dominance and submission are extracted and perceived from social targets.

Additionally, we found a consistent general effect whereby participants who were allowed greater time to perceive the stimuli also took more time to respond to them. Parallel to our main effect of increased accuracy with greater viewing time, this could suggest a speedaccuracy tradeoff effect (eg Wickelgren 1977). However, when controlling for condition, the relationship between accuracy and response latency uniformly became non-significant. Thus, within conditions, there did not appear to be a speed-accuracy tradeoff between the individual participants. Rather, the effects of accuracy and response latency seemed relatively distinct. An alternative explanation for the relationship between response latency and exposure time may therefore be that the speed of presentation of the stimulus images paced participants' responses. Indeed, the speed of presentation would have affected the duration and pace of the overall experiment. Participants viewing more rapid presentations may have consequently experienced more anticipation or vigilance for successive stimulus presentations, resulting in shorter latencies to respond to the stimuli. That said, in the majority of tests that we conducted, the effects for response latency largely rested within the difference between the self-paced versus speeded-duration conditions, suggesting that any linear effect might have been an artefact of this difference. Further work is surely needed to fully explore how changes in stimulus presentation duration affect the speed of perceivers' responses, particularly considering that differences in methodology (ie the combination of viewing and decision time for the self-paced response latencies) between the speeded and self-paced conditions likely contributed greatly to the presence of these effects.

Whereas the current work utilized posed expressions of dominance and submission, it would also be valuable to measure these effects using naturally-occurring stimulus cues. Although other research has investigated judgments of traits (including dominance) at speeded durations (eg Rule et al 2009b), those judgments were based on structural cues of non-expressive faces. A merging of the current and previous work would therefore explore how natural expressions of dominance in bodies and faces are assessed, such as those culled from individuals who self-report dominant (versus submissive) dispositions, or individuals actively engaged in dominant versus subordinate behavioral roles (see also Hall et al 2001). 
Such future work might also consider measuring perceptions of dominance with forced-choice categorizations, instead of making ratings along a continuous scale. Doing so would allow for calculations of accuracy separately for each stimulus type (eg, dominant, submissive), rather than relying on relative comparisons between the groups as in the sensitivity correlations used here. This would also allow for an analysis using signal detection theory, which would permit not only an estimation of accuracy but also of response bias. This might provide additional information about the process through which perceivers evaluate dominance and submission from facial and bodily cues. Similarly, additional work might seek to resolve some of the inconsistencies between the face and body stimuli used in the present work (eg multiple versions of the body stimuli, different numbers of face versus body stimuli, and differences in size between the face and body stimuli) to ensure that these effects generalize beyond the stimuli used here.

In conclusion, dominance is an important social dimension along which we perceive others and form impressions about them (eg Mazur 2005). Consistent with an ecological approach to understanding social perception (McArthur and Baron 1983), the present data demonstrated that people are able to distinguish posed cues that signal dominant and submissive behavior at levels significantly greater than chance under both physical and temporal constraints. These findings suggest that we may be particularly adept at perceiving social cues with important ecological implications for survival, such as those communicating social and physical dominance.

Acknowledgments. This research was supported in part by a National Sciences and Engineering Research Council grant (NSERC \#419593) to NOR and a National Institute of Aging grant (NIMH Award \#1 R01AG035028-01) to RBA Jr. The authors would like to thank Sela Kleiman and David Pham for their assistance with experiment preparation and data collection.

\section{References}

Ambady N, Bernieri F J, Richeson J A, 2000 "Toward a histology of social behavior: Judgmental accuracy from thin slices of the behavioral stream" Advances in Experimental Social Psychology 32 201-271

Bar M, Neta M, Linz H, 2006 "Very first impressions" Emotion 6 269-278

Baron-Cohen S, Riviere A, Fukushima M, French D, Hadwin J, Cross P, Bryant C, Sotillo M, 1996 "Reading the mind in the face: A cross-cultural and developmental study" Visual Cognition 3 39-59

Buhrmester M, Kwang T, Gosling S D, 2011 “Amazon's Mechanical Turk: A new source of inexpensive, yet high-quality, data?" Perspectives on Psychological Science 6 3-5

Burgoon J K, Buller D B, Hale J L, de Turck M A, 1984 "Relational messages associated with nonverbal behaviors" Human Communication Research 10 351-378

Burgoon J K, Dunbar N E, 2006 "Nonverbal expressions of dominance and power in human relationships", in The Sage Handbook of Nonverbal Communication Eds V Manusov, M L Patterson (Thousand Oaks, CA: Sage) pp 279-297

Carney D R, Cuddy A J C, Yap A J, 2010 "Power posing: Brief nonverbal displays affect neuroendocrine levels and risk tolerance" Psychological Science 21 1363-1368

Carney D R, Hall J A, Smith LeBeau L, 2005 "Beliefs about the nonverbal expression of social power" Journal of Nonverbal Behavior 29 105-123

Chiao J Y, Adams R B Jr, Tse P U, Lowenthal W T, Richeson J A, Ambady N, 2008 "Knowing who's boss: f MRI and ERP investigations of social dominance perception" Group Processes \& Intergroup Relations 11 201-214

Dijksterhuis A, Bos M W, Nordgren L F, van Baaren R B, 2006 "On making the right choice: The deliberation-without-attention effect" Science 311 1005-1007

Freeman J B, Rule N O, Adams R B Jr, Ambady N, 2009 "Culture shapes a mesolimbic response to signals of dominance and subordination that associates with behavior" NeuroImage 47 353-359 
Gelder B de, Tamietto M, 2011 "Faces, bodies, social vision as agent vision, and social consciousness", in The Science of Social Vision Eds R B Adams Jr, N Ambady, K Nakayama, S Shimojo (New York: Oxford University Press) pp 51-74

Gibson J J, 1979 The Ecological Approach to Visual Perception (New York: Harper \& Row)

Goldberg L R, Johnson J A, Eber H W, Hogan R, Ashton M C, Cloninger C R, Gough H G, 2006 "The international personality item pool and the future of public-domain personality measures" Journal of Research in Personality 40 84-96

Hall J A, Coats E J, Smith LeBeau L, 2005 "Nonverbal behavior and the vertical dimension of social relations: A meta-analysis" Psychological Bulletin 131 898-924

Hall J A, Smith LeBeau L, Gordon Reinoso J, Thayer F, 2001 "Status, gender, and nonverbal behavior in candid and posed photographs: A study of conversations between university employees" Sex Roles $44677-692$

Johnson K L, Gill S, Reichman V, Tassinary L G, 2007 "Swagger, sway, and sexuality: Judging sexual orientation from body motion and morphology" Journal of Personality and Social Psychology 93 321-334

Judd C M, Ryan C S, Park B, 1991 "Accuracy in the judgment of in-group and out-group variability" Journal of Personality and Social Psychology 61 366-379

Kappas A, Hess U, Barr C L, Kleck R E, 1994 "Angle of regard: The effect of vertical viewing angle on the perception of facial expressions" Journal of Nonverbal Behavior 18 263-328

Keating C F, 1985 "Gender and the physiognomy of dominance and attractiveness" Social Psychology Quarterly 48 61-67

Keating C F, Mazur A, Segall M H, Cysneiros P G, Divale W T, Kilbride J E, Leahy P, Komin S, Thurman B, Wirsing R, 1981 "Culture and the perception of social dominance from facial expression" Journal of Personality and Social Psychology 40 615-626

Lassiter G D, Lindberg M J, Gonzalez-Vallejo C, Belleza F S, Phillips N D, 2009 "The deliberationwithout-attention effect: Evidence for an artifactual interpretation" Psychological Science 20 671-675

McArthur L Z, Baron R M, 1983 “Toward an ecological theory of social perception” Psychological Review $90215-238$

Macrae C N, Martin D, 2007 "A boy primed Sue: Feature-based processing and person construal" European Journal of Social Psychology 37 793-805

Macrae C N, Milne A B, Bodenhausen G V, 1994 "Stereotypes as energy-saving devices: A peek inside the cognitive toolbox" Journal of Personality and Social Psychology 66 37-47

Mazur A, 2005 The Biosociology of Dominance and Deference (Lanham, MD: Rowman \& Littlefield)

Meeren H K M, van Heijnsbergen C C R J, de Gelder B, 2005 "Rapid perceptual integration of facial expression and emotional body language" Proceedings of the National Academy of Sciences of the USA $10216518-16523$

Mignault A, Chaudhuri A, 2003 "The many faces of a neutral face: Head tilt and perception of dominance and emotion" Journal of Nonverbal Behavior 27 111-132

Moscovitch M, Winocur G, Behrmann M, 1997 "What is special about face recognition? Nineteen experiments on a person with visual object agnosia and dyslexia but normal face recognition" Journal of Cognitive Neuroscience 9 555-604

Mueller U, Mazur A, 1996 "Facial dominance of West Point cadets as a predictor of later military rank" Social Forces $74823-850$

Neuberg S L, Fiske S T, 1987 "Motivational influences on impression formation: Outcome dependency, accuracy-driven attention, and individuating processes" Journal of Personality and Social Psychology 53 431-444

Ohman A, 1986 "Face the beast and fear the face: Animal and social fears as prototypes for evolutionary analyses of emotion" Psychophysiology 23 123-145

Olson I R, Marshuetz C, 2005 "Facial attractiveness is appraised at a glance" Emotion 5 498-502

Raines R S, Hechtman S B, Rosenthal R, 1990 "Physical attractiveness of face and voice: Effects of positivity, dominance, and sex" Journal of Applied Social Psychology 20 1558-1578

Rinn W E, 1991 "Neuropsychology of facial expression", in Fundamentals of Nonverbal Behavior Eds R S Feldman, B Rime (New York: Oxford University Press) pp 3-30 
Rule N O, Ambady N, 2008 "Brief exposures: Male sexual orientation is accurately perceived at 50 ms" Journal of Experimental Social Psychology 44 1100-1105

Rule N O, Ambady N, 2009 “She's got the look: Inferences from female chief executive officers' faces predict their success" Sex Roles 61 644-652

Rule N O, Ambady N, Adams R B Jr, Macrae C N, 2008 "Accuracy and awareness in the perception and categorization of male sexual orientation" Journal of Personality and Social Psychology 95 $1019-1028$

Rule N O, Ambady N, Hallett K C, 2009a "Female sexual orientation is perceived accurately, rapidly, and automatically from the face and its features" Journal of Experimental Social Psychology $\mathbf{4 5}$ $1245-1251$

Rule N O, Ambady N, Adams R B Jr, 2009b "Personality in perspective: Judgmental consistency across orientations of the face" Perception 38 1688-1699

Rule N O, Ambady N, Adams R B Jr, Ozono H, Nakashima S, Yoshikawa S, Watabe M, 2010 "Polling the face: Prediction and consensus across cultures" Journal of Personality and Social Psychology 98 1-15

Schmid Mast M, 2001 "Gender differences and similarities in dominance hierarchies in same-gender groups based on speaking time" Sex Roles 44 537-556

Schmid Mast M, Hall J A, 2004 "Who is the boss and who is not? Accuracy of judging status" Journal of Nonverbal Behavior 28 145-165

Tiedens L Z, Fragale A R, 2003 "Power moves: Complementarity in dominant and submissive nonverbal behavior" Journal of Personality and Social Psychology 84 558-568

Wickelgren W A, 1977 "Speed-accuracy tradeoff and information processing dynamics" Acta Psychologica 41 67-85

Zebrowitz L A, 1997 Reading Faces: Window to the Soul? (Boulder, CO: Westview)

Zebrowitz L A, Collins M A, 1997 "Accurate social perception at zero acquaintance: The affordances of a Gibsonian approach" Personality and Social Psychology Review $1204-223$ 